\title{
What should I do about my patient's gall stones?
}

\author{
AR Dennison, D Azoulay, N Oakley, H Baer, JA Paraskevopoulos, \\ GJ Maddern
}

\begin{abstract}
Summary
The problem of benign biliary disease is one that causes significant morbidity and social economic strain in the western world. The classical treatment, cholecystectomy, has been challenged by various medical and surgical techniques in a seemingly random nature. The development of the treatment of gall stone disease is reviewed by analysis of published studies over the last 20 years. The advantages and disadvantages are discussed as an overview and summary of the current management of gall stone disease in the light of our knowledge of its malignant potential.
\end{abstract}

Keywords: gall stones, management options, cholecystectomy

Leicester General Hospital NHS Trust, Leicester, LE5 4PW, UK

AR Dennison

Hôpital Paul Brousse, BP 2000, 94804

Villejuif, Paris, France

D Azoulay

Lincoln County Hospital, Lincoln, UK N Oakley

Inselspital, Berne 3010, Switzerland H Baer

Athens Medical Centre, Athens, Greece JA Paraskevopoulos

Queen Elizabeth Hospital, Woodville, South Australia 5011

GJ Maddern

Accepted 1 June 1995
The last two decades have witnessed extraordinary pharmacological and technical advances which have dramatically altered our approach to the management of gall stones. These developments drew the attention of the medical profession and general public alike to the significant morbidity associated with classical cholecystectomy. Nevertheless it remains difficult to define clear indications for many of the alternative treatments, particularly in view of the lack of long-term studies and details not only of procedure-related complications but also of problems associated with the diseased gall bladder being in situ for a prolonged period. The situation is further complicated in some countries where market forces seem to play an inordinate part in the management of this particular problem.

It is neverthless remarkable that the known association between gall stones and the development of gall bladder cancer has seemed to play such a small part in the decision-making process regarding the treatment of symptomatic gall bladder disease. The aim of this article is to review the alternatives to traditional cholecystectomy in the light of what is presently known about the process leading to carcinoma of the gall bladder.

\section{Open cholecystectomy}

The option of open cholecystectomy for symptomatic gall stones has been with us since the surgical revolution in late 19th century following the advent of anaesthesia and Lister's introduction of his principle of antisepsis. First performed successfully in 1882 by CJA Langenbuch, ${ }^{1}$ chief surgeon in the Lazarus Hospital of Berlin, by 1886 this had become a routine procedure in the hands of surgeons such as Hans $\mathrm{Kehr}^{2}$ who had performed over 1000 by his death in 1916. The cause was further championed by both Moynihan in England and Mayo in America and by the early 1920s became the procedure of choice for symptomatic gall stones despite a significant mortality and morbidity.

Early mortality rates were reported at $6.6 \%^{3}$ although by 1952 this had decreased to $1.8 \%{ }^{4}$ and recent studies show it to be dropping to around $0.5 \%{ }^{4-6}$ Pulmonary embolism and deep vein thrombosis were reported at $1 \%,{ }^{7-9}$ adding to specific complications such as common bile duct damage, ${ }^{7,10,11}$ retained stone, ${ }^{12}$ and bile leak.7,9 Wound complications included infection, herniation and dehiscence, ${ }^{7,9,10,13-15}$ with both the classical Kocher subcostal incision or the right paramedian incision causing respiratory compromise with subsequent risk of atelactasis or pneumonia. ${ }^{9,10,14,16}$

As a reaction to this morbidity the classical incisions gave way in the 1980 s to that of the 'minilap' using a 5-cm muscle-splitting incision and a no-touch technique in a 'well'. ${ }^{17,18}$ Improving both local and systemic morbidity ${ }^{19}$ breathed life into the open cholecystectomy in the face of advances in dissolution therapy and extracorporeal shock-wave lithotripsy.

\section{Dissolution therapy}

It is nearly 20 years since the study from Danzinger et al showed that oral chenodeoxycholic acid could produce cholesterol stone dissolution. ${ }^{20}$ This report was responsible for stimulating many groups in the confident expectation that non-operative methods for managing gall stones would eventually become firmly established. Consequently, after a number of small studies, a large randomised multicentre study the National Co-operative Study was embarked upon in the US to define in particular the efficacy and indication for chenodeoxycholic acid. Unfortunately this study failed to confirm much of the initial enthusiasm and whilst demonstrating that, in selected cases, gall stones were eradicated, it also revealed that even when treatment was reserved for 'ideal' candidates, after two 


\begin{tabular}{|c|c|}
\hline \multicolumn{2}{|c|}{$\begin{array}{l}\text { Cholecystectomy: } \\
\text { complications }\end{array}$} \\
\hline - mortality & $\begin{array}{l}0.1 \%<50 \text { years } \\
0.6 \% 50-70 \text { years } \\
2.5 \%>70 \text { years }\end{array}$ \\
\hline $\begin{array}{l}\text { - pulmonary } \\
\text { embolism } \\
\text { - deep vein } \\
\text { thrombosis } \\
\text { - wound infectio } \\
\text { (paramedian }\end{array}$ & $\begin{array}{l}0.4 \% \\
1-3 \% \\
2-10 \% \\
>\text { subcostal) }\end{array}$ \\
\hline $\begin{array}{l}\text { - hernia } \\
\text { - atelectasis }\end{array}$ & $\begin{array}{l}5-13 \% \\
(\text { vertical }>\text { subcostal) } \\
5-20 \% \\
(\text { subcostal }>\text { vertical) } \\
(\text { minilap }<4 \%)\end{array}$ \\
\hline - common bile du & act damage $0.1 \%$ \\
\hline
\end{tabular}

Box 1

\begin{tabular}{|l|}
\hline Dissolution therapy: \\
the ideal patient \\
\hline - stones: cholesterol, $<15 \mathrm{~mm}$ \\
diameter, non calcified \\
- functioning gall bladder \\
- compliant \\
- non-obese \\
\hline
\end{tabular}

Box 2

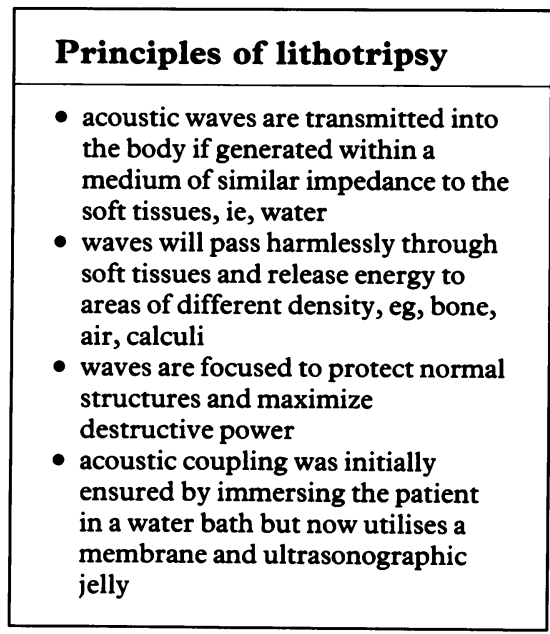

Box 3

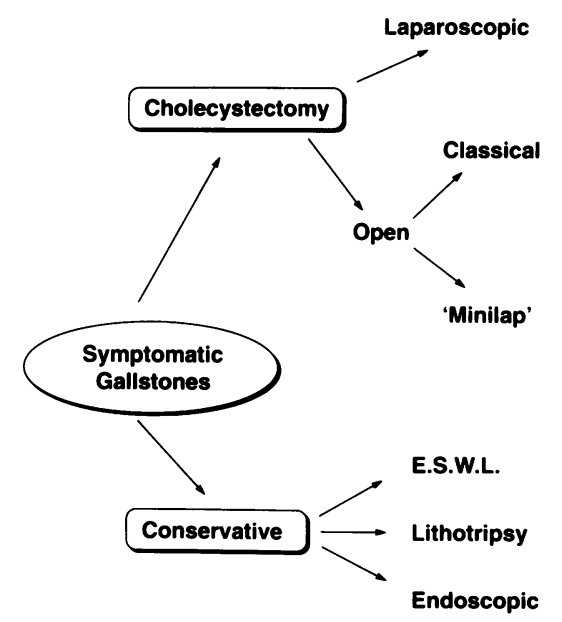

Figure 1 Treatment options for symptomatic gall stones (E.S.W.L. = extracorporeal shock-wave lithotripsy) years the rate of disappearance was a disappointing $13 \%{ }^{21}$ This low response rate in combination with frequent side effects did not indicate an effective alternative therapy to traditional cholecystectomy which persisted unchallenged as the treatment of choice until the advent of extracorporeal shock wave lithotripsy. However, the more recent availability of ursodeoxycholic acid, which is believed to be more effective and less troubled by side effects than chenodeoxycholic acid, ${ }^{22}$ and the use of extracorporeal shock-wave lithotripsy and dissolution together, has expanded the potential use of these agents. ${ }^{23}$

\section{Extracorporeal shock wave lithotripsy}

It was not until 1986 that Sauerbruch et al in Munich published a report showing that, in combination with oral bile acids, extracorporeal shock-wave lithotripsy had completely eradicated the stones from gall bladders in six out of nine subjects. ${ }^{24}$ In 1988 encouraging results were reported by the same group on the first 175 patients. This study not only showed the stones were no longer present in over $90 \%$ of the subjects within eight months of treatment, but also demonstrated the most suitable patients by showing that when single stones of less than $2 \mathrm{~cm}$ were treated, the rate rose to $95 \%$. Perhaps more significant, however, was the finding in the study that only $28 \%$ of all patients reviewed were considered to fulfil the criteria for treatment. ${ }^{23}$ It has subsequently become evident that relaxing the treatment criteria dramatically reduces the effectiveness of extracorporeal shock-wave lithotripsy and may explain why preliminary reports of studies from the US have been less encouraging than those from Munich. ${ }^{25}$

It is likely that the natural history of the gall stone fragments after treatment will in part explain differences in early studies. The treatment aims to fragment stones to less than half a centimetre in diameter which, in theory at least, should then be naturally eliminated. The belief that this was uncommon (indeed if this were true why did all gall stones not do the same during their formation) led the Munich group to include oral bile salts in the original protocol. A study from Schoenfield et al confirmed that the addition of ursodeoxycholic acid doubled the effectiveness of the treatment. ${ }^{25}$ These findings cast some doubt on the future of the treatment, especially in view of the advances occurring concomitantly in other areas. The main problem was the inability to fragment stones to less than half a centimetre in diameter in more than $50 \%$ of the patients treated. Furthermore, at six months only $20 \%$ of patients originally considered suitable (5\% of all patients referred) demonstrated complete stone clearance. ${ }^{25}$

\section{Percutaneous gall bladder stone treatment}

The development of 'mother and baby' endoscopes (initially developed for the clearance of stones from the common bile duct ${ }^{26}$ ) facilitated the introduction of solvents into the cystic duct. Agents such as methyl-tert-butyl ether will effectively dissolve cholesterol stones ${ }^{27}$ and this method seems likely to be fraught with less problems than previously attempted percutaneous approaches. ${ }^{28}$ Unfortunately these percutaneous approaches, enthusiastically adopted by radiologists and urologists, are limited by the composition of the stones when attempting dissolution, and the size and composition when attempting extraction in a dilated duct. ${ }^{28}$ These limitations led to the investigation of devices capable of destroying gall stones in situ, but even early reports with this type of equipment have indicated that significant morbidity might be expected. ${ }^{29}$

The lack of a wholly successful treatment for gall stones in situ, combined with fears about long-term problems from damaged mucosa (both recurrent stone disease and malignancy) contributed to the enthusiasm with which laparoscopic cholecystectomy was greeted.

\section{Laparoscopic cholecystectomy}

Since its introduction in France by Phillippe Mouret in Lyon in 1987, laparoscopic cholecystectomy has emerged as an attractive alternative to traditional cholecystectomy for symptomatic gall stone disease. The main advantages of this technique are the cosmetic aspects, minimal wound pain with complete resolution within a few days, the short hospital stay, the ability of many patients to return to work within a week of operation ${ }^{30}$ and the improvement of postoperative respiratory function compared to both classical ${ }^{31,32}$ and 'mini-lap' cholecystectomies. ${ }^{33}$ Initially, the proportion of patients suitable for laparoscopic cholecystectomy was believed to be approximately $80 \%{ }^{34}$ However, with increasing experience the list of absolute contraindications has clearly diminished, making laparoscopic cholecystectomy suitable for nearly all patients 


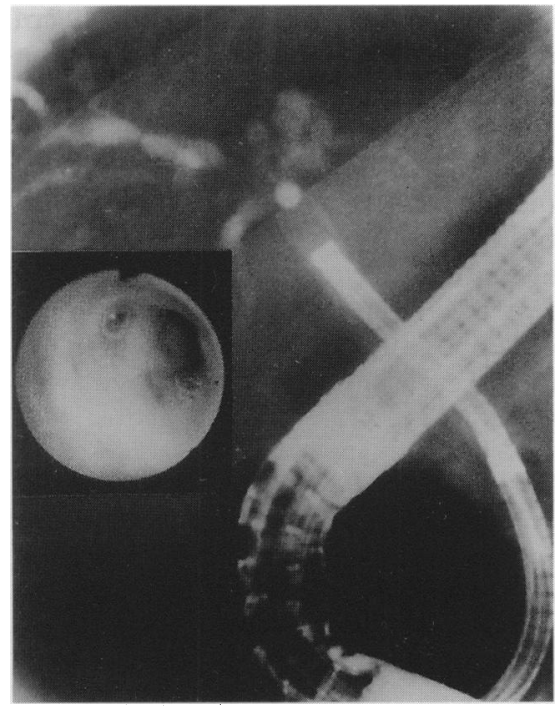

Figure 2 Radiograph of 'baby' endoscope passing up common bile duct from 'mother' endoscope. Inset: view of mouth of cystic duct. From Practical Gastrointestinal Endoscopy, PB Cotton and CB Williams, by kind permission Blackwell Scientific Press

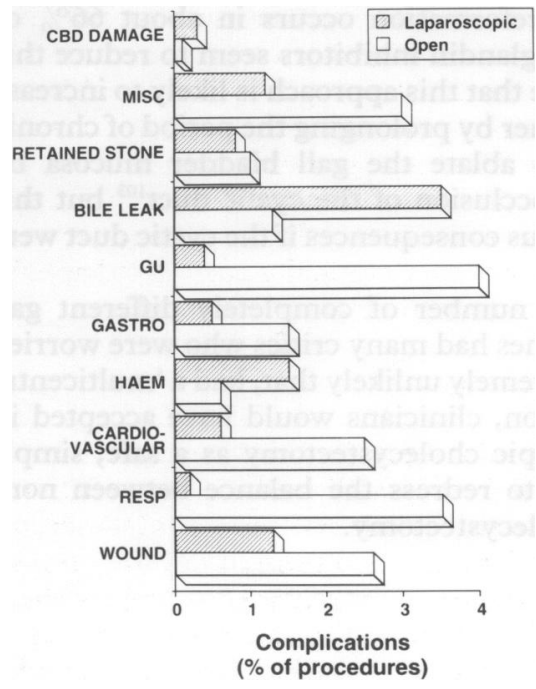

Figure 3 Complications of open vs laparoscopic cholecystectomy $(\mathrm{CBD}=\mathrm{com}-$ mon bile duct; misc = miscellaneous, gu = genitourinary; gastro = gastrointestinal; haem = haematological; resp = respiratory) with symptomatic cholelithiasis. At present, patients requiring concomitant upper abdominal operations or not tolerating general anaesthesia are excluded (the latter condition could be overcome, at least in selected cases, with the use of epidural anaesthesia). ${ }^{35}$

There is a remarkable consistency in the figures produced by different series. The Southern Surgeons Club in the US conducted a prospective study of 1518 patients who underwent laparoscopic cholecystectomy by a total of 59 surgeons. The overall complication rate was $5.1 \%$ with a bile duct incidence of $0.5 \%$ and a conversion rate to traditional open cholecystectomy of $4.7 \%{ }^{36}$ Cuschieri et al reported the European experience by performing a retrospective survey of seven European centres involving 20 surgeons who undertook 1236 laparoscopic cholecystectomies. The total postoperative complication rate was $1.6 \%$ while conversion to open cholecystectomy was necessary in 45 patients $(3.6 \%){ }^{37}$

Despite the rapid and widespread acceptance, early data suggest that some complications are more common after laparoscopic cholecystectomy when compared to traditional cholecystectomy. The main area of concern with this procedure is bile duct injury, and the experience from several institutions reporting an overall rate between $0.3 \%$ and $0.6 \%{ }^{36-39}$ compared to only $0.1 \%$ in patients with traditional cholecystectomy. ${ }^{40}$ It must be remembered, however, that the above figures are those for surgeons still familiarising themselves with the technique. Whether this risk translates into a significant problem with bile duct strictures or patients with long-term sequelae of undetected bile duct injuries remains to be seen. It is generally accepted that only fully trained general surgeons with expertise in biliary surgery and an adequate training in laparoscopy should perform laparoscopic cholecystectomy. ${ }^{41}$ With a background of previous similar discussions for flexible endoscopy, the Board of Directors of the Society of American Gastrointestinal Endoscopic Surgeons has introduced guidelines for Granting of Privileges for Laparoscopic General Surgery. ${ }^{42}$ In accordance with this and with a view to influencing the widespread adoption of this new procedure, clinical laparoscopic training has been introduced into general surgery residency programmes. ${ }^{43}$

Finally, in the present era of National Health Service reforms and widespread redistribution of funds, the financial implications of laparoscopic cholecystectomy are clear with a cost-saving capital per patient (largely due to reduced hospital stay) of $£ 900 .{ }^{37}$ Utilising selection criteria which eliminate most high-risk patients it is estimated that $60 \%$ of all patients undergoing laparoscopic cholecystectomy could be done as true out-patients leading to even less expense and greater convenience for the patient. ${ }^{44}$

\section{Gall bladder carcinoma}

The last 30 years has seen 41 studies of gall bladder cancer appear in the literature giving details of almost 45000 patients. ${ }^{45-85}$ The motivation for most of these studies hinges not on the frequency of the tumour (which although the commonest biliary tract malignancy is still a rare tumour) but upon the dismal prognosis, irrespective of treatment, in all but the earliest lesions due to direct liver spread. The difficulty in achieving early detection of gall bladder cancer lies in the lack of any specific biochemical, clinical or radiological features. It is usually only advanced cases that present with suspicious symptoms (jaundice and unremitting pain), and $75 \%$ are found to be inoperable.$^{86}$ Indeed the overall survival at between 0 and $12.5 \%$ at five years (median $1.7 \%$ ) is only improved in those $15 \%$ of patients with tumours discovered incidentally subsequent to histological examination. ${ }^{87}$ In this respect the report of Bergdhal is typical in stating that in 32 patients with only mucosal or submucosal involvement, there was a $63.6 \%$ five-year survival and $45.5 \%$ 10-year survival following cholecystectomy alone. ${ }^{88}$ A similar series of Nevin et al was more encouraging, reporting an $86 \%$ five-year survival in patients with mucosal disease. ${ }^{46}$ These results probably explain the $30 \%$ increase in mortality from gall bladder carcinoma that has occurred in Sweden in the last 20 years where the rate of cholecystectomy has been reduced dramatically. The falling rate of cancer in the UK, USA and Canada ${ }^{88}$ where cholecystectomy rates have risen, suggest that approximately one gall bladder carcinoma will be cured or prevented per 100 cholecystectomies for gall stones. ${ }^{89}$ The available literature confirms the known predisposing factor for gall bladder cancer (choledochal cysts, ${ }^{90,91}$ long-standing inflammatory bowel disease, ${ }^{92}$ xanthogranulomatous cholecystitis, ${ }^{93}$ 3,3chlorobenzidine exposure, ${ }^{93}$ previous biliary surgery, ${ }^{94}$ chronic salmonellosis, ${ }^{94}$ diffuse calcification, ${ }^{95}$ abnormal pancreaticobiliary anatomy, ${ }^{96}$ certain ethnic groups, ${ }^{97}$ and gall stones $(40-100 \%) \cdot{ }^{86,97}$ Although studies of the effect of gall stones have been hindered by their prevalence in developed countries, the relationship is not only a constant finding but depends upon the nature of the 


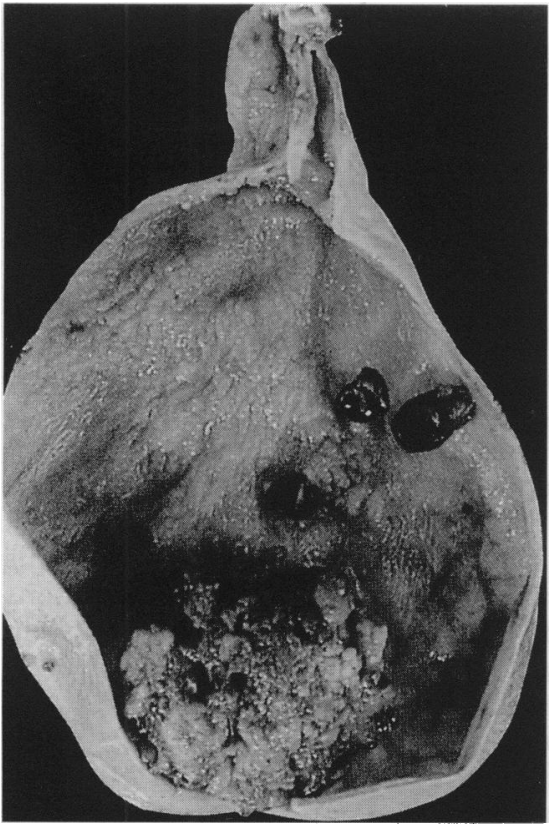

Figure 4 Carcinoma of gall bladder. A fungating, partly papillary tumour with three small pigment stones. From $A n$ atlas of gross pathology, CDM Fletcher, by kind permission Edward Arnold Ltd

\begin{tabular}{|l|}
\hline Key points \\
\hline Conservative therapy \\
- few ideal candidates \\
- high recurrence rate \\
- known associations with gall \\
bladder cancer \\
- minimal morbidity \\
Open surgery \\
- significant morbidity/mortality \\
- pathology removed \\
Laparoscopic cholecystectomy \\
- decreased mortality/morbidity \\
- rise in common bile duct injuries \\
- learning curve \\
- close control of training required \\
\hline
\end{tabular}

Box 4

1 Praderi RC. One hundred years of biliary surgery. Surg Gastroenterol 1982; 1: 269-87. 2 Kehr H Die praxis der Gallenwege: chirugie in wort und bild. Munich, Germany: JF Lehmann's Verlage, 1913

3 Heuer GJ. The factors leading to death in operations upon the gallbladder and bile ducts. Ann Surg 1934; 99: 881.

4 Glenn F, Hays DM. The causes of death flenn F, Hays DM. The causes of death nant disease. Surg Gynaecol Obstet 1952; 94: 283.

5 Gallbladder Survey Committee. 28,621 cholecystectomies in Ohio. Am f Surg 1970; 119: 714-7.

6 McSherry CK. Cholecystectomy: the gold standard. Am f Surg 1989; 158: 174-8.

7 Morgenstern L, Wong L, Berci G. Twelve hundred open cholecystectomies before the laparoscopic era. A standard for comparison. Arch Surg 1992; 127: 400-3.

8 Vuori EE. Treatment of cholecystitis: cholecystostomy or cholecystectomy. $A m \mathcal{F}$ Surg 1976; 132: 75-80.

9 Scher KS, Scott-Conner CEH. Complications of biliary surgery. Am Surg 1987; 53: 16-21. stones. The incidence of carcinoma increases two- to four-fold for $2.0-2.9 \mathrm{~cm}$ stones compared to stones of $1 \mathrm{~cm}$ and increases 10-fold for stones greater than $3 \mathrm{~cm} .{ }^{98}$ It has also been shown that cholesterol stones are most likely to be associated with the development of carcinoma. Despite the strong correlation between the two the causity of gall stones in the pathogenesis of gall bladder cancer is not yet fully understood. It is postulated that the chronic trauma and mucosal inflammation caused by gall stones lead to dysplasia and hence frank malignancy, with the accumulative risk of eventually developing carcinoma in a gall bladder containing stones estimated at $8 \%$ over the age of $50 . .^{99}$ These findings, together with work tracing the sequence from gall bladder adenoma to in situ malignancy, ${ }^{86}$ forms a basis for some reservations about the move away from traditional cholecystectomy.

\section{The present position}

The traditional upper abdominal cholecystectomy incision is unsightly, painful and associated with postoperative respiratory complications. Patients usually require a hospital stay of at least a week and full normal activity (particularly heavy manual work) is typically not restarted for several weeks. This latter problem infrequently produces considerable domestic and financial problems and is one of the main arguments in favour of the move to laparoscopic cholecystectomy.

Whilst laparoscopic cholecystectomy is a new procedure which has a considerable way to go before its' place in the surgical armamentarium is clearly defined, ${ }^{25,100}$ it nevertheless has clear advantages over traditional cholecystectomy. Further, unlike non-surgical options, removal of the gall bladder not only cures the disease, but at the same time eliminates the possibility of recurrence and the development of carcinoma due to diseased mucosa remaining in situ. The role of recurrent disease is indeed significant as, after destruction of stones or their removal, if follow-up is long enough, reformation occurs in about $66 \%$ of patients, ${ }^{101}$ although bile salts and prostaglandin inhibitors seem to reduce this problem. ${ }^{102}$ It seems reasonable to assume that this approach is likely to increase the risk of malignant transformation further by prolonging the period of chronic irritation. This has led to attempts to ablate the gall bladder mucosa by installation of a variety of agents after occlusion of the cystic duct ${ }^{103}$ but this approach could have predictably disastrous consequences if the cystic duct were imperfectly occluded.

The simultaneous development of a number of completely different gall bladder preserving conservative approaches had many critics who were worried about the lack of long-term data. It is extremely unlikely that, had a 'multicentre study' been constructed in similar fashion, clinicians would have accepted it. Fortunately the emergence of laparoscopic cholecystectomy as a safe, simple procedure in confident hands is likely to redress the balance between nonoperative treatments and traditional cholecystectomy.
10 Girard RM, Morin M. Open cholecystectomy: it's morbidity and mortality as a reference standard. Can f Surg 1993; 36: 75-80.

11 Henry ML, Carey LC. Complications of cholecystectomy. Surg Clin N Am 1983; 63: 1191-204.

12 Glenn F. Retained calculi within the biliary ductal system. Am Surg 1974; 1979: 528.

13 Sahlin S, Ahlberg T, Granstrom L, LjungSahlin S, Ahlberg T, Granstrom L, Ljungabsorbable suture for abdominal closure. $\mathrm{Br} \mathcal{F}$ Surg 1993; 80: 322-4.

14 Pemberton LB, Manax WG. Complications after vertical and transverse incisions for cholecystectomy. Surg Gynaecol Obstet 1971; 132: 892-4.

15 Larson GM, Vandertoll DJ. Approaches to repair of ventral hernia and full-thickness losses of the abdominal wall. Surg Clin N Am 1984; 64: 335-49.

16 Poe RH, Kallay MC, Dass T, Celebic A. Can post-operative pulmonary complications after elective cholecystectomy be predicted? $A m \mathcal{F}$ Med Sci 1988; 295: 29-34.
17 Goco IR, Chambers LG. 'Minicholecystectomy' and operative cholangiograms: a means of cost containment. Am Surg 1983; Mar: 143-5.

18 Merill JR. Minimal trauma cholecystectomy. A 'no-touch' procedure in a well. Am Surg 1988; 54: 256-61.

19 Lindell $P$, Hedenstierna G. Ventilation efficiency after different incisions for efficiency after different incisions for 142: $561-5$.

20 Danzinger RG, Hofmann AF, Schoenfield LJ Thistle JL. Dissolution of cholesterol gall stones by chenodeoxycholic acid. N Engl I Med 1972; 286: 1-8.

21 Schoenfield LJ, Lachin JM for the Steering Committee National Co-operative Gall Stone Study Group. Chenodiol (Chenodeoxycholic acid) for dissolution of gall stones: a controlled trial of efficacy and safety. Ann Intern Med 1981; 95: 257-82 
22 Roda E, Bazzoli F, Morselli Labate AM et al. Ursodeoxycholic acid versus chenodeoxycholic acid as cholesterol gall stone dissolving agents: a comparative randomised study. Hepatology 1982; 2: 804-10.

23 Sackman M, Delius M, Sauerbruch T, et al. Shockwave lithotripsy of gall bladder stones:
the first 175 patients. $N$ Engl $f$ Med 1988; 318: the first

24 Sauerbruch T, Delius M, Paumgartner G, et al. Fragmentation of gall stones by extracorporeal shock waves. $N$ Engl f Med 1986; 314: 818-22.

25 Schoenfield LJ, Berci G, Carnovale RL, et al. The effect of ursodiol on the efficacy and safety of extracorporeal shock-wave lithotripsy of gall stones. N Engl ₹ Med 1990; 323: 1239-45.

26 Simon DM, Brooks WS, Hersh T. Endoscopic sphincterotomy: a reappraisal. Am $\mathcal{f}$ Gastroenterol 1989; 84: 213-9.

27 Thistle JL, May GR, Bender CE, et al. Dissolution of cholesterol gall bladder stones by methyl-tert-butyl ether administered by per-
cutaneous transhepatic catheter. $N$ Engl $₹$ Med cutaneous transhepat

28 Griffith DP, Gleeson MJ. Percutaneous cholecystolithotomy: a logical progression of endourologic techniques. $\mathcal{F}$ Endourol 1989; 3 : 11-18.

29 Miller FJ, Kensey KR, Nash JE. Experimental percutaneous gall stone lithotripsy: results in swine. Radiology 1989; 170: 9856-7.

30 Cheslyn-Curtis S, Russell RCG. New trends in gall stone management. Br $\mathcal{F}$ Surg 1991; 78 143-9.

31 Schauer PR, Luna J, Ghiatas AA, Glen ME, Warren JM, Sirinek KR. Pulmonary function after laparoscopic cholecystectomy. Surgery after laparoscopic

32 Poulin EC, Mamazza J, Breton G, Fortin CL, Wabha R, Ergina P. Evaluation of pulmonary function in laparoscopic cholecystectomy. Surg Laparosc Endosc 1992; 2: 292-6.

33 McMahon AJ, Russel IT, Ramsay G et al. Laparoscopic and minilaparotomy cholecystectomy: a randomized trial comparing postoperative pain and pulmonary function. Surgery 1994; 115: 533-9.

34 Sauerbruch T, Paumgartner G. Gall bladder stones: management. Lancet 1991; 338: $1121-4$.

35 Schirmer BD, Edge SB, Dix J, Hyser MJ, Hanks JB, Jones RS. Laparoscopic cholecystectomy. Treatment of choice for cholecystectomy. Treatment of choice for 213: 665-77.

36 The Southern Surgeons Club. A prospective analysis of 1518 laparoscopic cholecystectomies. N Engl f Med 1991; 324: 1073-8.

37 Cuschieri A, Dubois F, Mouiel J, et al. The European experience with laparoscopic cholecystectomy. Am ₹ Surg 1991; 161: 385-7.

38 Smith EB. Complications of laparoscopic cholecystectomy. $\Im$ Natl Med Assoc 1992; 84, 880-2.

39 Caputo L, Aitken DR, Mackett MC, Robles AE. Iatrogenic bile duct injuries. The real incidence and contributing factors-implications for laparoscopic cholecystectomy. $\mathrm{Am}$ Surg 1992; 58: 766-71.

40 Cameron JL, Gadacz TR. Laparoscopic cholecystectomy. Ann Surg 1991; 213: 1-2.

41 Terblanche J. Laparoscopic cholecystectomy: a new milestone or a dangerous innovation? a new milestone or a dange

42 Dent TL. Training, credentialling and granting of clinical privileges for laparoscopic general surgery. Am $\mathcal{f}$ Surg 1991; 161: 399-403.

43 Bailey RW, Imembo AL, Zucker KA. Establishment of laparoscopic cholecystectomy 231-6.

44 Reddick EJ. Laparoscopic cholecystectomy in freestanding out patient centres. $\mathcal{f}$ Laparoendosc Surg 1992; 2: 65-7.

45 Fahim RB, McDonald JR, Richards JC, Ferris DO. Carcinoma of the gall bladder: a study on its modes of spread. Ann Surg 1962; 156: its modes

46 Nevin JE, Moran TJ, Kay S, King R. Carcinoma of the gall bladder; staging, treatment
and prognosis. Cancer 1976; 37: 141-8.

47 Tarpila E, Borch K, Kullman E, Liedberg G. Gall bladder cancer; current status in clinical practice. Eur ₹ Surg Oncol 1988; 14: 51-4.

48 Roberts JW, Daugherty SF. Primary carinom of the gall bladder. Surg Clin N Am 1986; 66: 743-9.

49 Tabet BJ. Primary carcinoma of the gall bladder, report of 47 cases. Am $\mathcal{F}$ Surg 1960; 100 365-71.

50 Stauch GO. Primary carcinoma of the gall bladder. Surgery 1960; 47: 368-83.
51 Gert PH. Primary carcinoma of the gall bladder; a thirty year summary. Ann Surg 1961; 153: 369-72

52 Bossart PA, Patterson AH, Zintel HA. Carcinoma of the gall bladder; a report of 76 cases. Am $₹$ Surg 1962; 103: 366-9.

53 Robertson WA, Carlisle BB. Primary carcinoma of the gall bladder; review of 52 cases. Am ₹ Surg 1967; 113: 738-42.

54 Litwin MS. Primary carcinoma of the gall bladder; a review of 78 patients. Arch Surg 1967; 95: 236-40.

55 Warren KW, Hardy KJ, O'Rourke MGE. Primary neoplasia of the gall bladder. Surg Gynecol Obstet 1968; 126: 1036-40.

56 Andrews EC, Bennett DE, Arhelger RB. Carcinoma of the gall bladder; report of 45 cases. South Med F 1969; 62: 573-8.

57 Tanga MR, Ewing JB. Primary malignant tumours of the gall bladder, report of 43 cases. Surgery 1970; 67: 418-26.

58 Hardy MA, Volk H. Primary carcinoma of the gall bladder; a ten year review. Am $\mathcal{F}$ Surg 1970 ; 120: 800-3.

59 Solan MJ, Jackson BT. Carcinoma of the gall bladder; a clinical appraisal and review of 57 cases. Br f Surg 1971; 58: 593-7.

60 Holmes SL, Mark JBD. Carcinoma of the gall bladder. Surg Gynecol Obstet 1971; 133: $561-4$.

61 Klein JB, Finck FM. Primary carcinoma of the gall bladder, review of 28 cases. Arch Surg 1972; 104: 769-72

62 Beltz WR, Condon RE. Primary carcinoma of the gall bladder. Am Surg 1974; 180: 180-4.

63 Balaroutsos C, Bastounis E, Karamanakos $P$, Golematis B. Primary carcinoma of the gall bladder; analysis of 22 cases. Am Surg 1974; 40: 605-8.

64 Ohlsson EG, Aronsen KF. Carcinoma of the gall bladder; a study of 181 cases. Acta Chirurg Scand 1974; 140: 475-80.

65 Moosa AR, Anaonost M, Hall AW, Moraldi A Skinnder DB. The continuing challenge of gall bladder cancer; survey of thirty years experience at the University of Chicago. Am $\mathcal{J}$ Surg 1975; 130: 57-62.

66 Prakash ATM, Sharma LK, Pandit PN. Primary carcinoma of the gall bladder. $\mathrm{Br} \mathcal{F}$ Surg 1975; 62: 33-6.

67 Donaldson LA, Busuttil A. A clinicopathological review of 68 carcinomas of the gall bladder. Br $\mathcal{F}$ Surg 1975; 62: 26-32.

68 Richard PF, Cantin J. Primary carcinoma of the gall bladder; study of 108 cases. Can F Surg 1976; 19: 27-32

69 Weiskopf J, Esselstyn CB. Carcinoma of the gall bladder; a 25 year review. Am $\mathcal{f}$ Gastroenterol 1976; 65: 522-7.

70 DoCarmo M, Perpetuo MO, Valdiviesco M, et al. Natural history study of gall bladder cancer. Cancer 1978; 42: 330-5.

71 Gupta S, Udupa KN, Gupta S. Primary carcinoma of the gall bladder; a review of 328 cases. I Surg Oncol 1980; 14: 35-44.

72 Shieh CJ, Dunn E, Standard JE. Primary carcinomas of the gall bladder; a review of a 16 year experience at the Waterbury Hospita
Health Centre. Cancer 1981; 47: 996-1004.

73 Tashiro S, Konno T, Michinaga $M$, et al. Primary carcinoma of the gall bladder; a review

74 Koo J, Wong J, Cheng FCY, Ong GB. Carcinoma of the gall bladder. Br F Surg 1981; 68: cinoma

75 Kelly TR, Chamberlain TR. Carcinoma of the gall bladder. Am $\mathcal{F}$ Surg 1982; 143: 737-41.

76. Wanebo HJ Castle WN, Fechner RE. Is carcinoma of the gall bladder a curable lesion? Ann Surg 1982; 195: 624-30.

77 Hamrick RE, Liner FJ, Hastings PR, Cohn I. Primary carcinoma of the gall bladder. Ann Surg 1982; 195: 270-3.

78 Klmaer TK, Max MH. Carcinoma of the gall bladder. Surg Gynecol Obstet 1983; 156: 641-5.

79 Morrow CE, Sutherland DER, Florack G Eisenberg MM, Grage TB. Primary gall bladder carcinoma; significance of subserosal lesions and results of aggressive surgical treatment and adjuvant chemotherapy. Surgery ment and adjuvant

80 Sons HU, Borchard F, Joel BS. Carcinoma of the gall bladder; autopsy findings in 287 cases and review of the literature. $\mathcal{Y}$ Surg Oncol 1985; 28: $199-206$

81 Shukla VK, Khandelwal C, Roy SK, Vaidya MP. Primary carcinoma of the gall bladder; a review of a 16 year period at the University Hospital. f Surg Oncol 1985; 28: 32-5.

82 Lowenfels AB, Lindstrom CB, Conway MJ Hastings PR. Gall stones and risk of gall bladder cancer. FNCI 1985; 75: 77-80.
83 Whetstone MR, Saltzstein EC, Mercer LC. Demographic characteristics of gall bladder cancer in an area endemic for biliary calculi. Am $\mathcal{F}$ Surg 1986; 152: 728-30.

84 White K, Kraybill WG, Lopez MJ. Primary carcinoma of the gall bladder. TNM staging
and prognosis. $\mathcal{F}$ Surg Oncol 1988; 39: 251-5.

85 Kimura W, Shimada H, Kuroda A, Morioka Y. Carcinoma of the gall bladder and extrahepatic bile duct in autopsy cases of the aged with special reference to its relationship to gall special reference to its relationship to gall
stones. Am $₹$ Gastroenterol 1989; 84: 386-90.

86 Ouchi K, Owada Y, Matsuno S, Sato T. Prognostic factors in the surgical treatment of gall bladder cancer. Surgery 1987; 101: 731-7.

87 Albores-Saavedra J, Henson DE. Tumours of the gall bladder and extrahepatic bile ducts. In: Atlas of tumor pathology. Fasc 22. Washington DC: Armed Forces Institute of Pathology, 1986; pp 17-123.

88 Bergdahl L. Gall bladder carcinoma first diagnosed at microscopic examination of gall bladders removed for presumed benign disease. Ann Surg 1980; 191: 19-22.

89 Diehl AK, Beral V. Cholecystectomy and changing mortality from gall bladder cancer. Lancet 1981; 2: 187-9.

90 Flanigan DP. Biliary cysts. Ann Surg 1975; 182: $635-43$

91 Tsuchiya R, Harada N, Ito $T$, et al. Malignant tumours in choledochal cysts. Ann Surg 1977; 186: 22-8.

92 Joffe N, Antonioli DA. Primary carcinoma of the gall bladder associated with chronic inflammatory bowel disease. Clin Radiol 1981; 32: 319-24.

93 Benbow EW. Xanthogranulomatous cholecystitis associated with carcinoma of the gall bladder. Postgrad Med F 1981; 65: 528-31.

94 Welton JC, Marr JS, Friedman SM. Association between hepatobiliary cancer and typhoid tion between hepatobiliary cancer and

95 Berk RN, Armbuster TG, Saltzstein SL. Carcinoma of the porcelain gall bladder. Radiology 1973; 106: 29-31.

96 Miyazaki K, Date K, Imamura S, Ogawa Y, Nakayama F. Familial occurrence of anomalous pancreatociobiliary duct union Gastroenterol 1989; 84: 176-81.

97 Maringhini A, Moreau JA, Melton LJ, Hench VS, Zinzmeister AR, Dimagno EP. Gall stones, gall bladder cancer and other gastrointestinal malignancies. Ann Intern Med 1987; 107: 30-5.

98 Diehl AK. Gall stone size and the risk of gall bladder cancer. $\mathcal{Y} A M A$ 1983; 250: 2323-6.

99 Piehler JM, Greichlow RW. Primary cancer of the gall bladder. Surg Gynaecol Obstet 1978; 147: 929 .

100 Miller TA. Gastrointestinal and biliary conditions. Am Coll Surg Bull 1990; 75: 16-20.

01 Villanova N, Bazzoli F, Taroni F, et al. Gall stone recurrence after successful oral bile acid treatment: a 12 year follow-up study and evaluation of longer-term post-dissolution

102 Lee SP, Carey MC , Lamont JT. Aspiring prevention of cholesterol gall stone information in prairie dogs. Science 1981; 211: 1429-31

103 Becker CD, Quenville NF, Burmenne HJ. Long term occlusion of the porcine cystic duct by means of endoluminal radio frequency electrocoagulation. Radiology 1988; 167: 63-8. 